\title{
Approach to solving mining machine selection problem by using grey theory
}

\begin{abstract}
The selection of a mining machine is a multiple-attribute problem that involves the consideration of numerous parameters of various origins. A common task in the mining industry is to select the best machine among several alternatives, which are frequently described both with numerical variables as well as linguistic variables.

Numerical variables are mostly related to the technical characteristics of the machines, which are available in detail in most cases. On the other hand, some equally important parameters such as price, reliability, support for service and spare parts, operating cost, etc., are not available at the required level for various reasons; hence, these can be considered uncertain information. For this reason, such information is described with linguistic variables.

This paper presents research related to overcoming this problem by using grey theory for selecting a proper mining machine. Grey theory is a well-known method used for multiple-attribute selection problems that involves a system in which parts of the necessary information are known and parts are unknown.
\end{abstract}

Key words: machine selection, grey theory, multiple-attribute, uncertain information, mining industry

\section{INTRODUCTION}

The selection of a mining machine is a multi-attribute decision-making problem that is an important issue for an effective production system. The most common approach is to evaluate several alternatives that should be ranked according to various criteria or attributes. For evaluating mining machines, several factors should be taken into consideration. The purpose of this task is to acquire the best possible alternative for the given restrictions.

The most common recent approach is the use of operational research methods such as the Analytical Hierarchical Process (AHP), Analytical Network Process (ANP), and Preference Ranking Or-ganization Method for Enrichment Evaluations (PROMETHEE) [1-5]. Some papers also suggested the application of fuzzy sets [6-7] or a more general approach to machinery selection [8].
However, there is still a difficulty when the criteria for selecting a machine are completely known or partially known; i.e., when some of the criteria or attributes can only be described by linguistic variables. The mining machine selection methodology presented in this paper incorporates both numerical and linguistic variables based on grey theory.

\section{METHODOLOGY}

The most common situation for decision makers in the mining industry is to act according to information based on some level of accuracy. The problem of selecting a machine based on its technical characteristics is the easiest one, since all the variables are defined with numerical values. In conventional multiattribute selection methods, the attribute ratings and attribute weights are precisely known [9-11]. 
In this case, the variables are easily transformed, compared, normalized, or evaluated. However, comparing some alternatives and their attributes can only be performed by linguistic variables. For example, an accurate performance comparison of machines from different manufacturers can only be done if the machines are operating under the same conditions with the same rock materials and with equal maintenance policies, etc. (which is seldom the case). Hence, mining industry professionals are constantly debating which machine is "better" or "poorer."

Adding to this, the confidentiality policies of mining companies furthermore reduce the accuracy of the information. Nevertheless, even reduced accuracy can generate some information such as some supplier who is "more" agile in after-market support (the delivery of spare parts) or some machine has "poorer" reliability in hard rocks. Again, an evaluation of such attributes can be done with linguistic variables.

Keeping in mind that the selection of machines is most often based on partially completely known information and partially on information with reduced accuracy, we have developed an approach based on grey theory. Grey theory is one of the methods used to study uncertainty problems with discrete data and incomplete information. In the theory, if the system information is fully known, the system is called a white system; if the information is totally unknown, the system is called a black system. A system with partially known information is called a grey system. Definitions, grey number operations, and procedures are described in detail and are wellknown [12], and this system is used in similar research such as $[13,14]$.

The main concept of the grey system is to reduce the uncertainty based on the available information as shown in Figure 1 to allow for a more reliable ranking of the alternatives.

The procedure for determining the rank of alternatives comprises of several steps (according to common grey system nomenclature) are as follows:

- allocation of weights (Tab. 1) and ratings (Tab. 2) to each of the attributes by a panel of experts and calculating the average value of these,

- establishment of grey decision matrix (D),

- normalizing the grey decision matrix $\left(\mathrm{D}^{*}\right)$ to compare the different evaluation measures,

- establishment of weighted normalized grey decision matrix $(\mathrm{V})$ to indicate the contiguous grades between the comparative series,

- composing the ideal alternative,

- calculation of grey possibility degree between alternatives and ideal alternative,

- ranking of alternatives according to grey possibility degree.

Table 1

\section{Scale of attribute weights}

\begin{tabular}{|l|c|c|}
\hline Very Low & 0 & 0.1 \\
\hline Low & 0.1 & 0.3 \\
\hline Medium Low & 0.3 & 0.4 \\
\hline Medium & 0.4 & 0.5 \\
\hline Medium High & 0.5 & 0.6 \\
\hline High & 0.6 & 0.9 \\
\hline Very High & 0.9 & 1 \\
\hline
\end{tabular}

Table 2

Scale of attribute ratings

\begin{tabular}{|l|c|c|}
\hline Very Poor & 0 & 1 \\
\hline Poor & 1 & 3 \\
\hline Medium Poor & 3 & 4 \\
\hline Fair & 4 & 5 \\
\hline Medium Good & 5 & 6 \\
\hline Good & 6 & 9 \\
\hline Very Good & 9 & 10 \\
\hline
\end{tabular}

Grey system

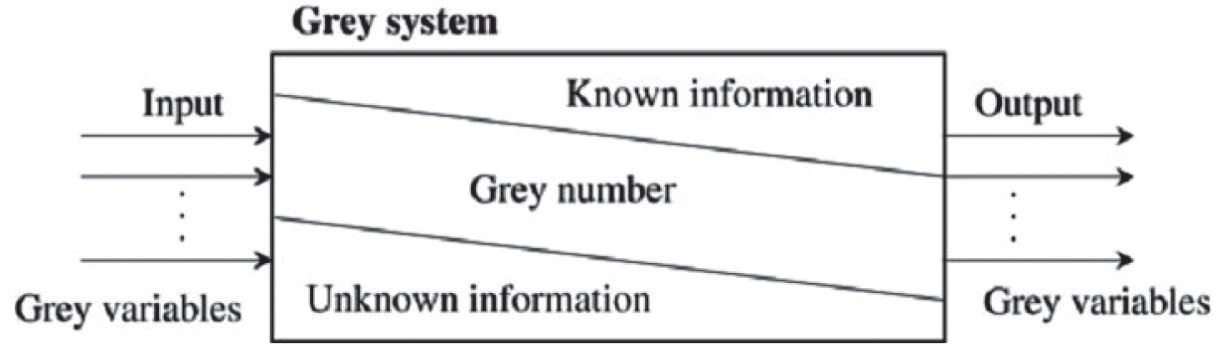

Fig. 1. Concept of grey system 
Having in mind all of the above, we are suggesting a different approach in the first step of the procedure for cases when alternatives are described by white and grey numbers. The panel of experts should not be included in the attribute ratings for white attributes. Ratings for white attributes should be allocated according to the scale given in Table 2 and by taking into account the location of a specific value within the range of alternatives (maximum and minimum) - direct ratings.

In this way, subjective judgement is further reduced, since complete information on a specific attribute is available. However, it should be noted that the panel of experts is included in the allocation of weights for all of the attributes regardless if they are white or grey.

An example of the described procedure is given below as a case study for ranking Load-Haul-Dump (LHD) machines.

\section{CASE STUDY - EXAMPLE}

In this example, we are considering five LoadHaul-Dump machines whose nine characteristics that will be used for ranking are given in Table 3 . The same problem is considered in one of the previous research, such as [15].

For ranking these machines, their technical characteristics are categorized into four attributes (A1 through A4), as elaborated in Table 4. These attributes will be considered as white attributes, and ratings of these attributes will be done in relation to one of the others instead of by the panel of experts.

Besides these, a further three grey attributes (A5, A6, and A7) will also be used for ranking the LHD machines (which are also elaborated in Table 4).

Table 3

Underground loaders and characteristics

\begin{tabular}{|l|c|c|c|c|c|c|c|c|c|}
\hline \multicolumn{1}{|c|}{ Machine } & $\begin{array}{c}\text { Bucket } \\
\text { volume } \\
{\left[\mathbf{m}^{\mathbf{3}}\right]}\end{array}$ & $\begin{array}{c}\text { Engine } \\
\mathbf{p o w e r} \\
{[\mathbf{k W}]}\end{array}$ & $\begin{array}{c}\text { Payload } \\
{[\mathbf{k g}]}\end{array}$ & $\begin{array}{c}\text { Machine } \\
\text { mass } \\
{[\mathbf{t}]}\end{array}$ & $\begin{array}{c}\text { Loading } \\
\mathbf{c y c l e} \\
{[\mathbf{s}]}\end{array}$ & $\begin{array}{c}\text { Velocity } \\
\mathbf{m a x} . \\
{[\mathbf{k m} / \mathbf{h}]}\end{array}$ & $\begin{array}{c}\text { Outside } \\
\text { turning } \\
\text { radius } \\
{[\mathbf{m m}]}\end{array}$ & $\begin{array}{c}\text { Inside } \\
\text { turning } \\
\text { radius } \\
{[\mathbf{m m}]}\end{array}$ & $\begin{array}{c}\text { Bucket } \\
\text { width } \\
{[\mathbf{m m}]}\end{array}$ \\
\hline Atlas Copco ST 3.5 & 3.4 & 136 & 6000 & 17.10 & 12.6 & 21.0 & 5446 & 2620 & 1956 \\
\hline Sandvik Tamrock Toro 006 & 3.0 & 142 & 6700 & 17.20 & 12.9 & 26.0 & 5600 & 3030 & 2100 \\
\hline GHH Fahrzeuge LF/6 & 3.0 & 136 & 6000 & 19.50 & 12.5 & 23.0 & 6022 & 3247 & 2040 \\
\hline Caterpillar R1300 & 3.4 & 123 & 6800 & 20.95 & 9.3 & 24.0 & 5741 & 2825 & 2400 \\
\hline Wuhan KHD-3 & 3.0 & 112 & 6500 & 17.20 & 13.5 & 23.0 & 6060 & 3274 & 2110 \\
\hline
\end{tabular}

Table 4

Attributes for ranking LHD machines

\begin{tabular}{|c|c|c|}
\hline Attribute & Type & Description \\
\hline Material handling (A1) & gain & $\begin{array}{l}\text { This attribute combines the bucket volume and payload capability of the LHD } \\
\text { machine. In this case study, these are combined into a single attribute by multi- } \\
\text { plying these characteristics }\end{array}$ \\
\hline Power to weight (A2) & gain & $\begin{array}{l}\text { This is a common parameter obtained by dividing the engine power }[\mathrm{kW}] \text { with the } \\
\text { mass of the machine }[\mathrm{t}]\end{array}$ \\
\hline Machine swiftness (A3) & gain & $\begin{array}{l}\text { This attribute is obtained by dividing the maximal velocity of the machine }(\mathrm{km} / \mathrm{h}- \\
\text { bigger is better) by the loading cycle }([\mathrm{s}]-\text { smaller is better }) \text {, providing a parameter } \\
\text { for evaluating the swiftness of a machine to achieve high production rates }\end{array}$ \\
\hline Maneuverability (A4) & loss & $\begin{array}{l}\text { This attribute is obtained by summing the inside and outside turning radii as well as } \\
\text { the bucket width. The smaller the value, the better, since the machine can turn in } \\
\text { narrower roadways }\end{array}$ \\
\hline Acquisition cost (A5) & loss & This is the price of the machine; hence, is the loss attribute - the smaller, the better \\
\hline $\begin{array}{l}\text { Service support } \\
\text { and availability of spare } \\
\text { parts (A6) }\end{array}$ & gain & $\begin{array}{l}\text { This attribute is envisaged for evaluating the manufacturer's presence on the market } \\
\text { in terms of the expertise of its staff, the quality of its, workshops, its storage } \\
\text { facilities, etc. }\end{array}$ \\
\hline Reliability of machine (A7) & gain & $\begin{array}{l}\text { This attribute is used for evaluating the operational capabilities of the machine; i.e., } \\
\text { evaluation of machine performance in actual operation }\end{array}$ \\
\hline
\end{tabular}


Ratings for these attributes will be established by the panel of experts as well as the attribute weights for all seven attributes.

In first step, a group of five experts allocated the weights for each attribute as given in Table 1, thus highlighting the importance of each specific attribute. These marks are used for calculating the range of the weights (min and max) for each attribute (Tab. 5). Further on, the same panel of experts assigned attribute ratings according to Table 2 for Attributes 5, 6, and 7 . Ratings for the first four attributes (A1-A4) are assigned in a process of "direct rating," meaning that these are established by comparing the attributes among themselves (thus eliminating subjectivity). For this reason, each rating for the first four attributes is an integer value, while the ratings for the remaining three attributes are calculated as average values (Tab. 6, grey decision matrix - D). A normalized grey decision matrix is given in Table 7 , which is established by taking into account that Attributes 4 and 5 are loss attributes (the smaller, the better), while all of the other attributes are gain attributes (larger values are better).

Multiplying the attribute weights (Tab. 5) and normalized grey decision matrix (Tab. 7) provides Weighted normalized grey decision matrix $(\mathrm{V})$, which is given in Table 8 . The values from this matrix are used to compose the Ideal referential alternative, which is given in Table 9.

Finally, the grey possibility degree is calculated for each attribute as related to the Ideal referential alternative. The grey possibility degrees are given in Table 10. The average values of the grey possibility degrees are given in the last column of Table 10.

Table 5

Attribute weights

\begin{tabular}{|c|c|c|c|c|c|c|c|}
\hline & E1 & E2 & E3 & E4 & E5 & $\min$ & $\max$ \\
\hline A1 & medium & medium & medium high & medium & medium & 0.42 & 0.52 \\
\hline $\mathrm{A} 2$ & medium high & medium & high & medium high & medium high & 0.50 & 0.64 \\
\hline $\mathrm{A} 3$ & high & medium high & medium high & very high & medium high & 0.60 & 0.74 \\
\hline A4 & medium & medium low & medium & medium low & medium high & 0.38 & 0.48 \\
\hline A5 & medium high & high & high & medium high & medium high & 0.54 & 0.72 \\
\hline A6 & high & medium & very high & medium & high & 0.58 & 0.76 \\
\hline A7 & very high & very high & medium & medium high & high & 0.66 & 0.80 \\
\hline
\end{tabular}

Table 6

\section{Grey decision matrix (D)}

\begin{tabular}{|l|c|c|c|c|c|c|c|c|c|c|c|c|c|c|}
\multicolumn{1}{c|}{} & \multicolumn{2}{c|}{$\mathbf{A 1}$} & \multicolumn{2}{c|}{$\mathbf{A 2}$} & \multicolumn{2}{c|}{$\mathbf{A 3}$} & \multicolumn{2}{c|}{ A4 } & \multicolumn{2}{c|}{ A5 } & \multicolumn{2}{c|}{ A6 } & \multicolumn{2}{c|}{ A7 } \\
\hline M1 & 6.0 & 9.0 & 6.0 & 9.0 & 4.0 & 5.0 & 4.0 & 5.0 & 5.4 & 7.2 & 5.4 & 7.2 & 5.6 & 7.8 \\
\hline M2 & 6.0 & 9.0 & 6.0 & 9.0 & 5.0 & 6.0 & 5.0 & 6.0 & 5.8 & 8.4 & 5.0 & 6.4 & 5.4 & 7.2 \\
\hline M3 & 5.0 & 6.0 & 5.0 & 6.0 & 4.0 & 5.0 & 6.0 & 9.0 & 5.6 & 7.8 & 4.8 & 5.8 & 5.4 & 7.2 \\
\hline M4 & 9.0 & 10.0 & 4.0 & 5.0 & 6.0 & 9.0 & 5.0 & 6.0 & 7.2 & 9.4 & 6.4 & 8.6 & 5.8 & 8.4 \\
\hline M5 & 5.0 & 6.0 & 5.0 & 6.0 & 4.0 & 5.0 & 6.0 & 9.0 & 4.0 & 5.0 & 4.4 & 5.8 & 3.6 & 4.6 \\
\hline
\end{tabular}

Table 7

Normalized grey decision matrix $\left(D^{*}\right)$

\begin{tabular}{|l|l|l|l|l|l|l|l|l|l|l|l|l|l|l|l|}
\multicolumn{1}{c|}{} & \multicolumn{2}{c|}{$\mathbf{A 1}$} & \multicolumn{2}{c|}{ A2 } & \multicolumn{2}{c|}{ A3 } & \multicolumn{2}{c|}{ A4 } & \multicolumn{2}{c|}{ A5 } & \multicolumn{2}{c|}{ A6 } & \multicolumn{2}{c|}{ A7 } \\
\hline M1 & 0.600 & 0.900 & 0.667 & 1.000 & 0.444 & 0.556 & 0.800 & 1.000 & 0.556 & 0.741 & 0.628 & 0.837 & 0.667 & 0.929 \\
\hline M2 & 0.600 & 0.900 & 0.667 & 1.000 & 0.556 & 0.667 & 0.667 & 0.800 & 0.476 & 0.690 & 0.581 & 0.744 & 0.643 & 0.857 \\
\hline M3 & 0.500 & 0.600 & 0.556 & 0.667 & 0.444 & 0.556 & 0.444 & 0.667 & 0.513 & 0.714 & 0.558 & 0.674 & 0.643 & 0.857 \\
\hline M4 & 0.900 & 1.000 & 0.444 & 0.556 & 0.667 & 1.000 & 0.667 & 0.800 & 0.426 & 0.556 & 0.744 & 1.000 & 0.690 & 1.000 \\
\hline M5 & 0.500 & 0.600 & 0.556 & 0.667 & 0.444 & 0.556 & 0.444 & 0.667 & 0.800 & 1.000 & 0.512 & 0.674 & 0.429 & 0.548 \\
\hline
\end{tabular}


Table 8

Weighted normalized grey decision matrix (V)

\begin{tabular}{|l|l|l|l|l|l|l|l|l|l|l|l|l|l|l|}
\cline { 2 - 15 } \multicolumn{1}{c|}{} & \multicolumn{2}{c|}{$\mathbf{A 1}$} & \multicolumn{2}{c|}{ A2 } & \multicolumn{2}{c|}{ A3 } & \multicolumn{2}{c|}{ A4 } & \multicolumn{2}{c|}{ A5 } & \multicolumn{3}{c|}{ A6 } & \multicolumn{2}{c|}{ A7 } \\
\hline M1 & 0.252 & 0.468 & 0.333 & 0.640 & 0.267 & 0.411 & 0.304 & 0.480 & 0.300 & 0.533 & 0.364 & 0.636 & 0.440 & 0.743 \\
\hline M2 & 0.252 & 0.468 & 0.333 & 0.640 & 0.333 & 0.493 & 0.253 & 0.384 & 0.257 & 0.497 & 0.337 & 0.566 & 0.424 & 0.686 \\
\hline M3 & 0.210 & 0.312 & 0.278 & 0.427 & 0.267 & 0.411 & 0.169 & 0.320 & 0.277 & 0.514 & 0.324 & 0.513 & 0.424 & 0.686 \\
\hline M4 & 0.378 & 0.520 & 0.222 & 0.356 & 0.400 & 0.740 & 0.253 & 0.384 & 0.230 & 0.400 & 0.432 & 0.760 & 0.456 & 0.800 \\
\hline M5 & 0.210 & 0.312 & 0.278 & 0.427 & 0.267 & 0.411 & 0.169 & 0.320 & 0.432 & 0.720 & 0.297 & 0.513 & 0.283 & 0.438 \\
\hline
\end{tabular}

Table 9

Ideal referential alternative

\begin{tabular}{|c|c|c|c|c|c|c|c|c|c|c|c|c|c|}
\hline \multicolumn{2}{|c|}{ A1 } & \multicolumn{2}{|c|}{ A2 } & \multicolumn{2}{|c|}{ A3 } & \multicolumn{2}{|c|}{ A4 } & \multicolumn{2}{|c|}{ A5 } & \multicolumn{2}{|c|}{ A6 } & \multicolumn{2}{|c|}{ A7 } \\
\hline 0.378 & 0.520 & 0.333 & 0.640 & 0.400 & 0.740 & 0.304 & 0.480 & 0.432 & 0.720 & 0.432 & 0.760 & 0.456 & 0.800 \\
\hline
\end{tabular}

Table 10

Grey possibility degree

\begin{tabular}{|c|c|c|c|c|c|c|c|c|}
\cline { 2 - 9 } \multicolumn{1}{c|}{} & $\mathbf{A 1}$ & $\mathbf{A 2}$ & $\mathbf{A 3}$ & $\mathbf{A 4}$ & $\mathbf{A 5}$ & $\mathbf{A 6}$ & $\mathbf{A 7}$ & Avg. \\
\hline M1 & 0.749 & 0.500 & 0.977 & 0.500 & 0.806 & 0.660 & 0.557 & 0.678 \\
\hline M2 & 0.749 & 0.500 & 0.813 & 0.739 & 0.878 & 0.760 & 0.621 & 0.723 \\
\hline M3 & 1.000 & 0.795 & 0.977 & 0.951 & 0.843 & 0.844 & 0.621 & 0.862 \\
\hline M4 & 0.500 & 0.949 & 0.500 & 0.739 & 1.000 & 0.500 & 0.500 & 0.670 \\
\hline M5 & 1.000 & 0.795 & 0.977 & 0.951 & 0.500 & 0.852 & 1.000 & 0.868 \\
\hline
\end{tabular}

These values are used for ranking the machines:

$\mathrm{M} 4<\mathrm{M} 1<\mathrm{M} 2<\mathrm{M} 3<\mathrm{M}$.

Therefore, it can be said that the fourth machine is the best among the considered five LHD machines.

\section{CONCLUSIONS}

Grey theory can be used for the selection or quality assessment of an arbitrary number of mining machines according to their technical characteristics. The introduction of the proposed approach further reduces subjectivity in the process, offering a more precise selection of the best solution. The presented procedure for the selection of a mining machine provided similar outcomes with the results of previous research. Therefore, combining grey and white numbers for the selection of machines as presented in this paper is justifiable and suitable for ranking an arbitrary number of alternatives/machines according to their technical characteristics and grey attributes.
The next step of the research will be to compare the results of a grey analysis with the results achieved using other decision-making methods.

\section{Acknowledgements}

The research described in this paper was performed during the development of the TR33025 technical development project. Development of this project is financed by Ministry of Science and Technological Development, Republic of Serbia.

The authors also acknowledge the European Union to make a first exchange mobility action between the University of Twente and the University of Belgrade Faculty of Mining and Geology possible, granting the ERASMUS+ project 2016-2-NL01KA107-034906.

\section{References}

[1] Dagdeviren M.: Decision making in equipment selection: an integrated approach with AHP and PROMETHEE, "Journal of Intelligent Manufacturing” 2008, 19: 397-406. 
[2] Lin Z.C., Yang C.B.: Evaluation of machine selection by the AHP method, "Journal of Materials Processing Technology" 1996, 57: 253-258.

[3] Paramasivam V. et al.: Decision making in equipment selection: an integrated approach with digraph and matrix approach, $A H P$ and $A N P$, "International Journal of Advanced Manufacturing Technology" 2011, 54: 1233-1244.

[4] Bascetin A.: A decision support system for optimal equipment selection in open pit mining: analytical hierarchy process, "Istanbul Üniversitesi, Mühendislik Fakültesi Yer Bilimleri Dergisi" 2003, 16, 2: 1-11.

[5] Mohamadabadi H.S. et al.: Development of a multi-criteria assessment model for ranking of renewable and non-renewable transportation fuel vehicles, "Energy" 2009, 24, 1: 112-125.

[6] Cebesoy T.: Hydraulic Excavator Selection Using Improved Quality Comparison Method, "Journal of Engineering Sciences (Mühendislik Bilimleri Dergisi)" 1999, 5, 1: 1001-1008.

[7] Hadi-Vencheha A., Mohamadghasemi A.: A new hybrid fuzzy multi-criteria decision-making model for solving the material handling equipment selection problem, "International Journal of Computer Integrated Manufacturing" 2015, 28, 5: 534-550.

[8] Basu A.S., Lineberry G.T.: Selection of Mobile Equipment for Underground Coal Mining: An Expert System Approach, "Mineral Resources Engineering" 1995, 4, 1: 71-88.

[9] Delgado M., Verdegay J.L., Vila M.A.: Linguistic decisionmaking models, "International Journal of Intelligent Systems" 1992, 7: 479-492.

[10] Hwang C.L., Yoon K.P.: Multiple Attributes Decision Making: Methods and Applications, Springer, Berlin - Heidelberg 1981.

[11] Kaufmann A., Gupta M.M.: Introduction to Fuzzy Arithmetic, Theory and Applications, Van Nostrand Reinhold, New York 1991.

[12] Liu S., Lin Y.: Grey systems Theory and Applications, Springer, Berlin - Heidelberg 2010.

[13] Bhattacharyya R.: A Grey Theory Based Multiple Attribute Approach for $R \& D$ Project Portfolio Selection, "Fuzzy Information and Engineering" 2015, 7: 211-225.
[14] Li G-D. et al.: A grey-based decision-making approach to the supplier selection problem, "Mathematical and Computer Modelling" 2007, 46: 573-581.

[15] Milisavljević V., Medenica D., Čokorilo V., Ristović I.: New Approach to Equipment Quality Evaluation Method with Distinct Function, "Thermal Science" 2015, 20, 2: 743-752.

VLADIMIR MILISAVLJEVIĆ, prof. Faculty of Mining and Geology

University of Belgrade

Đušina 7, 11000 Belgrade,

Serbia

vladimir.milisavljevic@rgf.bg.ac.rs

ALBERTO MARTINETTI, prof. Faculty of Engineering Technology University of Twente PO BOX 217, 7500 AE Enschede, the Netherlands a.martinetti@utwente.nl

ALEKSANDAR CVJETIĆ, prof. Faculty of Mining and Geology University of Belgrade Đušina 7, 11000 Belgrade, Serbia aleksandar.cvjetic@rgf.bg.ac.rs 


\title{
Metoda rozwiązywania problemów związanych z doborem maszyn górniczych na podstawie teorii szarych systemów
}

\begin{abstract}
Wybór maszyn górniczych to złożony problem, wymagająy rozważenia wielu różnych parametrów. Jednym z najważniejszych zadań w przemyśle górniczym jest wybór najlepszych spośród kilkunastu dostępnych maszyn, które często opisywane są zarówno za pomoca zmiennych numerycznych, jak i zmiennych lingwistycznych.

Zmienne numeryczne zwykle sa zwiazane z charakterystyka techniczna maszyn, która $w$ większości przypadków jest dostępna w szczegótach. $Z$ drugiej strony niektóre równie ważne parametry, takie jak cena, niezawodność, serwis i części zamienne, koszty operacyjne itd. $z$ wielu przyczyn nie sa dostępne na wymaganym poziomie, stąd należy je uważać za informacje niepewne. Dlatego też informacje te opisywane sa za pomoca zmiennych lingwistycznych.

Niniejszy artykut przedstawia badania mające na celu przezwyciężenie tego problemu $z$ wykorzystaniem teorii szarych systemów do wyboru odpowiednich maszyn górniczych. Teoria szarych systemów to dobrze znana metoda stosowana w przypadku problemów wyboru wielokryteriowego, gdzie część informacji jest znana, a część pozostaje nieznana.
\end{abstract}

Słowa kluczowe: wybór maszyn, teoria szarych systemów, wielokryteriowy, informacje niepewne, przemyst wydobywczy

\section{WPROWADZENIE}

Wybór maszyn górniczych to wielokryteriowy problem związany z podejmowaniem ważnych decyzji dla efektywnego systemu produkcji. Najczęściej spotykane podejście w tej kwestii to rozważenie kilkunastu możliwości, które należy ocenić według różnych kryteriów. W przypadku oceny maszyn górniczych należy uwzględnić współczynniki. Celem tego zadania jest uzyskanie najlepszej możliwej alternatywy dla określonych ograniczeń.

Najczęściej spotykanym ostatnio podejściem jest stosowanie metod optymalizacyjnych, takich jak analityczny proces hierarchiczny (AHP), analityczny proces sieciowy (ANP) i metoda Promethee) [1-5]. W niektórych pracach sugeruje się również stosowanie zbiorów rozmytych [6-7] lub bardziej ogólne podejście do wyboru maszyn [8].

Trudności występują, kiedy kryteria wyboru maszyn są znane całkowicie i częściowo, czyli kiedy nie- które kryteria można opisać tylko za pomocą zmiennych lingwistycznych. Metodologia wyboru maszyn górniczych przedstawiona w niniejszej pracy obejmuje zarówno zmienne numeryczne, jak i lingwistyczne na podstawie teorii szarych systemów.

\section{METODOLOGIA}

Decydenci w przemyśle górniczym zwykle działają na podstawie informacji na jakimś poziomie dokładności. Wybór maszyn oparty na ich charakterystyce technicznej stanowi najłatwiejszy problem, jako że wszystkie zmienne określane są wartościami numerycznymi. W konwencjonalnych wielokryteriowych metodach wyboru oceny kryteriów i ich wagi są dokładnie znane [9-11]. W takim przypadku zmienne można łatwo przekształcać, porównywać, normalizować czy oceniać. Jednak porównanie niektórych alternatyw i ich kryteriów można przeprowadzić tylko 
za pomocą zmiennych lingwistycznych. Na przykład maszyny od różnych producentów można porównać w sposób dokładny tylko wtedy, gdy pracują w tych samych warunkach, na tym samym materiale skalnym, przy przestrzeganiu takie samej polityki w kwestii konserwacji itd., co należy do rzadkości. Dlatego też fachowcy w branży górniczej zwykle dyskutują, która maszyna jest „lepsza” lub „gorsza”.

Dodatkowo polityka firm górniczych w zakresie poufności przyczynia się do jeszcze mniejszej dokładności informacji. Niemniej jednak, nawet przy mniejszej dokładności można wygenerować pewne informacje, takie jak to, że jakiś dostawca jest bardziej „sprawny” w kwestii serwisu posprzedażowego (dostawa części zamiennych), czy to, że niektóre maszyny odznaczają się mniejszą niezawodnością w warunkach eksploatacji skał trudnourabialnych. W tym przypadku ocena pewnych kryteriów wiąże się ze stosowaniem zmiennych lingwistycznych.

Mając na uwadze fakt, że wybór maszyn najczęściej opiera się częściowo na informacjach dobrze znanych, a częściowo na informacjach o obniżonej dokładności, opracowano metodę z wykorzystaniem teorii szarych systemów. Teoria szarych systemów to jedna z metod wykorzystywanych do badania problemów niepewności oparta na danych dyskretnych i niekompletnych informacjach. W teorii tej, jeżeli informacja o systemie jest w pełni znana, system nazywa się białym systemem, jeśli natomiast informacja jest całkowicie nieznana, system ten nazywa się czarnym. W sytuacji gdy informacje są częściowo znane, system nazywany jest szarym. Definicje, operacje na szarych liczbach i procedury zostały szczegółowo opisane i są dobrze znane [12], zaś system ten używany jest w podobnych badaniach, takich jak [13, 14].

Główną koncepcją systemu szarych układów jest zmniejszenie niepewności na podstawie dostępnych informacji, jak pokazano na rysunku 1 , w celu umożliwienia bardziej wiarygodnej oceny możliwości.
Procedura określania oceny dostępnych możliwości obejmuje kilkanaście kroków (zgodnie z powszechną nomenklaturą szarych systemów):

- przydział wag (tab. 1) i ocen (tab. 2) do każdego z kryteriów przez panel ekspertów i obliczenie ich średniej wartości,

- ustanowienie szarej macierzy decyzyjnej (D),

- normalizacja szarej macierzy decyzyjnej (D*) w celu porównania różnych miar oceny,

- ustanowienie ważonej znormalizowanej szarej macierzy decyzyjnej (V) do wskazania sąsiednich ocen pomiędzy seriami porównawczymi,

- komponowanie idealnej alternatywy,

- wyliczenie prawdopodobnego stopnia szarości pomiędzy wszystkimi możliwościami a alternatywą idealną,

- ocena dostępnych opcji zgodnie z prawdopodobnym stopniem szarości.

Tabela 1

Skala wag kryteriów

\begin{tabular}{|l|c|c|}
\hline Bardzo niska & 0 & 0,1 \\
\hline Niska & 0,1 & 0,3 \\
\hline Średnio niska & 0,3 & 0,4 \\
\hline Średnia & 0,4 & 0,5 \\
\hline Średnio wysoka & 0,5 & 0,6 \\
\hline Wysoka & 0,6 & 0,9 \\
\hline Bardzo wysoka & 0,9 & 1 \\
\hline
\end{tabular}

Tabela 2

Skala ocen kryteriów

\begin{tabular}{|l|l|l|}
\hline Bardzo slaba & 0 & 1 \\
\hline Slaba & 1 & 3 \\
\hline Średnio słaba & 3 & 4 \\
\hline Umiarkowana & 4 & 5 \\
\hline Średnio dobra & 5 & 6 \\
\hline Dobra & 6 & 9 \\
\hline Bardzo dobra & 9 & 10 \\
\hline
\end{tabular}

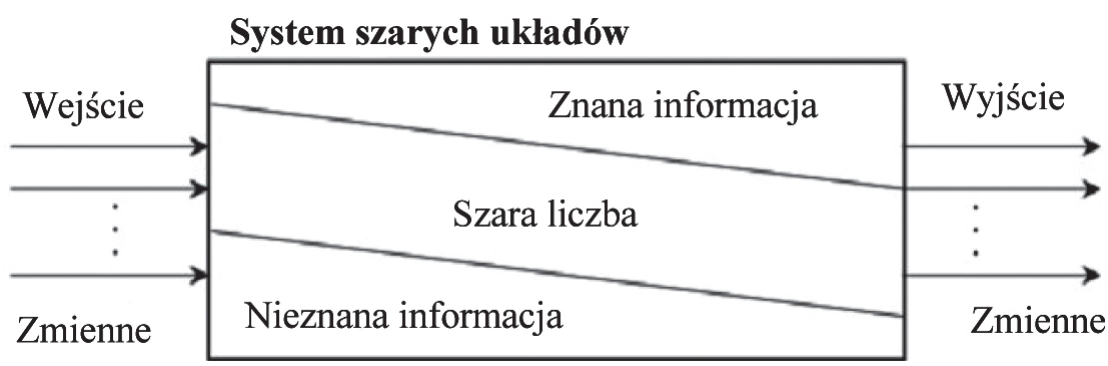

Rys. 1. Koncepcja układów szarego systemu 
Mając powyższe na względzie, proponuje się inne podejście jako pierwszy krok procedury dla przypadków, kiedy opcje opisane są za pomocą białych i szarych wartości. Panel ekspertów nie powinien być włączany do oceny białych kryteriów. Oceny dla białych kryteriów należy przydzielać zgodnie ze skalą podaną w tabeli 2 i uwzględniając lokalizację konkretnej wartości w zakresie alternatyw (maksymalna i minimalna) - oceny bezpośrednie.

W ten sposób subiektywny osąd zostaje ograniczony, jako że dostępne są kompletne informacje na temat określonego kryterium. Należy jednak zauważyć, że panel ekspertów jest zaangażowany w przydzielanie wag dla wszystkich kryteriów, niezależnie od tego czy są one białe czy szare.

Poniżej podano przykład opisanej procedury jako stadium przypadku dla oceny ładowarek łyżkowych (LHD).

\section{STUDIUM PRZYPADKU - PRZYKŁAD}

W niniejszym przykładzie rozważamy ładowarki łyżkowe, których główną charakterystykę, wykorzystywaną do oceny, podano $w$ tabeli 3 . Ten sam problem rozważany jest $\mathrm{w}$ jednym z poprzednich badań [15].

Aby ocenić działanie tych maszyn, ich charakterystykę techniczną dzieli się na cztery kryteria (od A1 do A4), jak przedstawiono w tabeli 4. Kryteria te będą uważane za białe kryteria, a ich ocena będzie dokonywana na podstawie wzajemnego porównania, a nie panelu ekspertów.

Oprócz tego do oceny ładowarek łyżkowych będą użyte trzy szare kryteria (A5, A6 i A7), które również zostały wyjaśnione w tabeli 4 . Oceny tych kryteriów oraz ich wagi dla wszystkich siedmiu kryteriów będą ustalane przez panel ekspertów.

Tabela 3

Ladowarki podziemne i ich charakterystyka

\begin{tabular}{|l|c|c|c|c|c|c|c|c|c|}
\hline \multicolumn{1}{|c|}{ Maszyna } & $\begin{array}{c}\text { Pojemność } \\
\text { lyżki } \\
{\left[\mathbf{m}^{\mathbf{3}}\right]}\end{array}$ & $\begin{array}{c}\text { Moc } \\
\text { silnika } \\
{[\mathbf{k W}]}\end{array}$ & $\begin{array}{c}\text { Ladunek } \\
\text { użyteczny } \\
{[\mathbf{k g}]}\end{array}$ & $\begin{array}{c}\text { Masa } \\
\text { maszyny } \\
{[\mathbf{t}]}\end{array}$ & $\begin{array}{c}\text { Cykl } \\
\text { ladowania } \\
{[\mathbf{s}]}\end{array}$ & $\begin{array}{c}\text { Maks. } \\
\text { prędkość } \\
{[\mathbf{k m} / \mathbf{h}]}\end{array}$ & $\begin{array}{c}\text { Promień } \\
\text { skrętu } \\
\text { zewnętrzny } \\
{[\mathbf{m m}]}\end{array}$ & $\begin{array}{c}\text { Promień } \\
\text { skrętu } \\
\text { wewnętrzny } \\
{[\mathbf{m m}]}\end{array}$ & $\begin{array}{c}\text { Szer. } \\
\text { lyżki } \\
{[\mathbf{m m}]}\end{array}$ \\
\hline Atlas Copco ST 3.5 & 3,4 & 136 & 6000 & 17,10 & 12,6 & 21,0 & 5446 & 2620 & 1956 \\
\hline $\begin{array}{l}\text { Sandvik Tamrock } \\
\text { Toro 006 }\end{array}$ & 3,0 & 142 & 6700 & 17,20 & 12,9 & 26,0 & 5600 & 3030 & 2100 \\
\hline $\begin{array}{l}\text { GHH Fahrzeuge } \\
\text { LF/6 }\end{array}$ & 3,0 & 136 & 6000 & 19,50 & 12,5 & 23,0 & 6022 & 3247 & 2040 \\
\hline Caterpillar R1300 & 3,4 & 123 & 6800 & 20,95 & 9,3 & 24,0 & 5741 & 2825 & 2400 \\
\hline Wuhan KHD-3 & 3,0 & 112 & 6500 & 17,20 & 13,5 & 23,0 & 6060 & 3274 & 2110 \\
\hline
\end{tabular}

Tabela 4

Kryteria oceny ladowarek

\begin{tabular}{|c|c|c|}
\hline Kryterium & Rodzaj & Opis \\
\hline $\begin{array}{l}\text { Transport bliski } \\
\text { materiałów (A1) }\end{array}$ & zysk & $\begin{array}{l}\text { To kryterium łączy objętość łyżki i możliwości ładowarki w zakresie ładunku użytecznego. } \\
\text { W tym przypadku są one połączone w jedno kryterium przez pomnożenie ich cech cha- } \\
\text { rakterystycznych }\end{array}$ \\
\hline $\begin{array}{l}\text { Stosunek mocy } \\
\text { do masy (A2) }\end{array}$ & zysk & $\begin{array}{l}\text { Jest to popularny parametr uzyskiwany przez podzielenie mocy silnika }[\mathrm{kW}] \text { przez masę ma- } \\
\text { szyny }[\mathrm{t}]\end{array}$ \\
\hline $\begin{array}{l}\text { Szybkość maszyny } \\
\text { (A3) }\end{array}$ & zysk & $\begin{array}{l}\text { To kryterium uzyskiwane jest przez podzielenie maksymalnej prędkości maszyny ([km/h] - } \\
\text { większy jest lepszy) przez cykl ładowania ([s] - mniejszy jest lepszy), stanowi on parametr } \\
\text { umożliwiający ocenę szybkości maszyny w osiąganiu dużego wydobycia }\end{array}$ \\
\hline Zwrotność (A4) & strata & $\begin{array}{l}\text { To kryterium uzyskiwane jest przez zsumowanie wewnętrznego i zewnętrznego promienia } \\
\text { skrętu z szerokością łyżki. Mniejsza wartość jest lepsza, ponieważ maszyna może skręcać na } \\
\text { węższych drogach }\end{array}$ \\
\hline Koszt nabycia (A5) & strata & Jest to cena maszyny, a zatem jest to kryterium straty - im mniejsza, tym lepsza \\
\hline $\begin{array}{l}\text { Serwis i dostępność } \\
\text { części zapasowych (A6) }\end{array}$ & zysk & $\begin{array}{l}\text { To kryterium jest przewidziane do oceny obecności producenta na rynku pod względem } \\
\text { wiedzy specjalistycznej personelu, jakości warsztatów, magazynów itd. }\end{array}$ \\
\hline $\begin{array}{l}\text { Niezawodność } \\
\text { maszyny (A7) }\end{array}$ & zysk & $\begin{array}{l}\text { To kryterium wykorzystywane jest do oceny zdolności operacyjnej maszyny, tj. oceny wy- } \\
\text { dajności maszyny w trakcie rzeczywistej eksploatacji }\end{array}$ \\
\hline
\end{tabular}


W pierwszym kroku grupa pięciu ekspertów przydzieliła wagi do każdego kryterium, co wyszczególniono w tabeli 1, podkreślając w ten sposób znaczenie określonego kryterium. Oceny te używane są do obliczania zakresu wag (min. i maks.) dla każdego kryterium (tab. 5). Następnie ten sam panel ekspertów przydzielił oceny kryterium zgodnie $\mathrm{z}$ tabelą 2 dla kryteriów A5, A6 i A7. Oceny dla pierwszych czterech kryteriów (A1-A4) przydzielane są w procesie „oceny bezpośredniej”, co oznacza, że są one ustalane przez porównanie kryteriów pomiędzy sobą, eliminując $w$ ten sposób subiektywność. $\mathrm{Z}$ tego względu każda ocena dla pierwszych czterech kryteriów jest liczbą całkowitą, natomiast oceny dla pozostałych trzech kryteriów są wyliczane jako wartość średnia (tabela 6, szara macierz decyzyjna- D). Znormalizo- wana szara macierz decyzyjna podana jest w tabeli 7 jest ona ustalana przez uwzględnienie, że kryteria 4 i 5 są kryteriami straty (mniejszy jest lepszy), podczas gdy wszystkie inne kryteria to kryteria zysku (większy jest lepszy).

Pomnożenie wag kryteriów (tab. 5) i znormalizowanej szarej macierzy decyzyjnej (tab. 7) daje ważoną znormalizowaną szarą macierz decyzyjną (V), która podana jest w tabeli 8 . Wartości tej macierzy używane są do porównywania idealnej alternatywy referencyjnej, która przedstawiona jest w tabeli 9.

Na końcu wylicza się stopień możliwej szarości dla każdego kryterium w stosunku do idealnej alternatywy referencyjnej. Stopnie możliwej szarości podane są w tabeli 10. Średnie wartości stopni możliwej szarości podane są w ostatniej kolumnie tabeli 10.

Tabela 5

\section{Wagi kryteriów}

\begin{tabular}{|l|l|l|l|l|l|l|l|}
\cline { 2 - 8 } \multicolumn{1}{c|}{} & \multicolumn{1}{c|}{ E1 } & \multicolumn{1}{c|}{ E2 } & \multicolumn{1}{c|}{ E3 } & \multicolumn{1}{c|}{ E4 } & \multicolumn{1}{c|}{ min } & max \\
\hline A1 & średni & średni & średni & średni & średni & 0,42 & 0,52 \\
\hline A2 & średni & średni & wysoki & średni & średni & 0,50 & 0,64 \\
\hline A3 & wysoki & średni & średnio & bardzo wysoki & średni & 0,60 & 0,74 \\
\hline A4 & średni & średnio niski & średni & średni & średni & 0,38 & 0,48 \\
\hline A5 & średni & wysoki & wysoki & średni & średni & 0,54 & 0,72 \\
\hline A6 & wysoki & średni & bardzo wysoki & średni & wysoki & 0,58 & 0,76 \\
\hline A7 & bardzo wysoki & bardzo wysoki & średni & średni & wysoki & 0,66 & 0,80 \\
\hline
\end{tabular}

Tabela 6

\section{Szara macierz decyzyjna (D)}

\begin{tabular}{|l|c|c|c|c|c|c|c|c|c|c|c|c|c|c|}
\multicolumn{1}{c|}{} & \multicolumn{2}{c|}{$\mathbf{A 1}$} & \multicolumn{2}{c|}{ A2 } & \multicolumn{2}{c|}{ A3 } & \multicolumn{2}{c|}{ A4 } & \multicolumn{2}{c|}{ A5 } & \multicolumn{2}{c|}{ A6 } & \multicolumn{2}{c|}{ A7 } \\
\hline M1 & 6,0 & 9,0 & 6,0 & 9,0 & 4,0 & 5,0 & 4,0 & 5,0 & 5,4 & 7,2 & 5,4 & 7,2 & 5,6 & 7,8 \\
\hline M2 & 6,0 & 9,0 & 6,0 & 9,0 & 5,0 & 6,0 & 5,0 & 6,0 & 5,8 & 8,4 & 5,0 & 6,4 & 5,4 & 7,2 \\
\hline M3 & 5,0 & 6,0 & 5,0 & 6,0 & 4,0 & 5,0 & 6,0 & 9,0 & 5,6 & 7,8 & 4,8 & 5,8 & 5,4 & 7,2 \\
\hline M4 & 9,0 & 10,0 & 4,0 & 5,0 & 6,0 & 9,0 & 5,0 & 6,0 & 7,2 & 9,4 & 6,4 & 8,6 & 5,8 & 8,4 \\
\hline M5 & 5,0 & 6,0 & 5,0 & 6,0 & 4,0 & 5,0 & 6,0 & 9,0 & 4,0 & 5,0 & 4,4 & 5,8 & 3,6 & 4,6 \\
\hline
\end{tabular}

Tabela 7

Znormalizowana szara macierz decyzyjna (D*)

\begin{tabular}{|l|c|c|c|c|c|c|c|c|c|c|c|c|c|c|}
\multicolumn{1}{c|}{} & \multicolumn{2}{c|}{ A1 } & \multicolumn{2}{c|}{ A2 } & \multicolumn{2}{c|}{ A3 } & \multicolumn{2}{c|}{ A4 } & \multicolumn{2}{c|}{ A5 } & \multicolumn{2}{c|}{ A6 } & \multicolumn{2}{c|}{ A7 } \\
\hline M1 & 0,600 & 0,900 & 0,667 & 1,000 & 0,444 & 0,556 & 0,800 & 1,000 & 0,556 & 0,741 & 0,628 & 0,837 & 0,667 & 0,929 \\
\hline M2 & 0,600 & 0,900 & 0,667 & 1,000 & 0,556 & 0,667 & 0,667 & 0,800 & 0,476 & 0,690 & 0,581 & 0,744 & 0,643 & 0,857 \\
\hline M3 & 0,500 & 0,600 & 0,556 & 0,667 & 0,444 & 0,556 & 0,444 & 0,667 & 0,513 & 0,714 & 0,558 & 0,674 & 0,643 & 0,857 \\
\hline M4 & 0,900 & 1,000 & 0,444 & 0,556 & 0,667 & 1,000 & 0,667 & 0,800 & 0,426 & 0,556 & 0,744 & 1,000 & 0,690 & 1,000 \\
\hline M5 & 0,500 & 0,600 & 0,556 & 0,667 & 0,444 & 0,556 & 0,444 & 0,667 & 0,800 & 1,000 & 0,512 & 0,674 & 0,429 & 0,548 \\
\hline
\end{tabular}


Tabela 8

Ważona znormalizowana szara macierz decyzyjna (V)

\begin{tabular}{|l|l|l|l|l|l|l|l|l|l|l|l|l|l|l|}
\multicolumn{1}{c|}{} & \multicolumn{2}{c|}{ A1 } & \multicolumn{2}{c|}{ A2 } & \multicolumn{2}{c|}{ A3 } & \multicolumn{2}{c|}{ A4 } & \multicolumn{2}{c|}{ A5 } & \multicolumn{2}{c|}{ A6 } & \multicolumn{2}{c|}{ A7 } \\
\hline M1 & 0,252 & 0,468 & 0,333 & 0,640 & 0,267 & 0,411 & 0,304 & 0,480 & 0,300 & 0,533 & 0,364 & 0,636 & 0,440 & 0,743 \\
\hline M2 & 0,252 & 0,468 & 0,333 & 0,640 & 0,333 & 0,493 & 0,253 & 0,384 & 0,257 & 0,497 & 0,337 & 0,566 & 0,424 & 0,686 \\
\hline M3 & 0,210 & 0,312 & 0,278 & 0,427 & 0,267 & 0,411 & 0,169 & 0,320 & 0,277 & 0,514 & 0,324 & 0,513 & 0,424 & 0,686 \\
\hline M4 & 0,378 & 0,520 & 0,222 & 0,356 & 0,400 & 0,740 & 0,253 & 0,384 & 0,230 & 0,400 & 0,432 & 0,760 & 0,456 & 0,800 \\
\hline M5 & 0,210 & 0,312 & 0,278 & 0,427 & 0,267 & 0,411 & 0,169 & 0,320 & 0,432 & 0,720 & 0,297 & 0,513 & 0,283 & 0,438 \\
\hline
\end{tabular}

Tabela 9

\section{Idealna alternatywa referencyjna}

\begin{tabular}{|c|c|c|c|c|c|c|c|c|c|c|c|c|c|}
\hline \multicolumn{2}{|c|}{ A1 } & \multicolumn{2}{|c|}{ A2 } & \multicolumn{2}{|c|}{ A3 } & \multicolumn{2}{|c|}{ A4 } & \multicolumn{2}{|c|}{ A5 } & \multicolumn{2}{|c|}{ A6 } & \multicolumn{2}{|c|}{ A7 } \\
\hline 0,378 & 0,520 & 0,333 & 0,640 & 0,400 & 0,740 & 0,304 & 0,480 & 0,432 & 0,720 & 0,432 & 0,760 & 0,456 & 0,800 \\
\hline
\end{tabular}

Tabela 10

Możliwy stopień szarości

\begin{tabular}{|c|c|c|c|c|c|c|c|c|}
\cline { 2 - 9 } \multicolumn{1}{c|}{} & A1 & A2 & A3 & A4 & A5 & A6 & A7 & Avg, \\
\hline M1 & 0,749 & 0,500 & 0,977 & 0,500 & 0,806 & 0,660 & 0,557 & 0,678 \\
\hline M2 & 0,749 & 0,500 & 0,813 & 0,739 & 0,878 & 0,760 & 0,621 & 0,723 \\
\hline M3 & 1,000 & 0,795 & 0,977 & 0,951 & 0,843 & 0,844 & 0,621 & 0,862 \\
\hline M4 & 0,500 & 0,949 & 0,500 & 0,739 & 1,000 & 0,500 & 0,500 & 0,670 \\
\hline M5 & 1,000 & 0,795 & 0,977 & 0,951 & 0,500 & 0,852 & 1,000 & 0,868 \\
\hline
\end{tabular}

Wartości używane są do oceny maszyn to:

M4 $<$ M1 $<$ M2 < M3 < M5.

Można zatem stwierdzić, że czwarta maszyna jest najlepsza spośród rozważanych pięciu ładowarek.

\section{WNIOSKI}

Teoria szarych systemów może być wykorzystywana do wyboru lub oceny jakości dowolnej liczby maszyn górniczych zgodnie $\mathrm{z}$ ich charakterystyką techniczną. Wprowadzenie proponowanej metody zmniejsza subiektywizm w procesie oferowania bardziej dokładnego wyboru najlepszego rozwiązania. Przedstawiona procedura wyboru maszyn górniczych zapewniła wyniki podobne do tych, które uzyskano w poprzednich badaniach, a zatem połączenie szarych i białych liczb do wyboru maszyn, jak przedstawiono w niniejszej pracy, jest uzasadnione i nadaje się do oceny dowolnej liczby innych dostępnych maszyn zgodnie z ich techniczną charakterystyką i szarymi kryteriami. Na- stępnym krokiem badania będzie porównanie wyników szarej analizy z wynikami uzyskanymi przy użyciu innych metod podejmowania decyzji.

Podziękowania

Badania opisane w niniejszej pracy zostały przeprowadzone w trakcie opracowywania projektu rozwoju technicznego TR33025. Opracowanie finansowane przez Ministerstwo Nauki i Rozwoju Technicznego w Republice Serbii.

Autorzy składają również podziękowania Unii Europejskiej za umożliwienie pierwszej wymiany pomiędzy Uniwersytetem Twente a Wydziałem Górnictwa i Geologii Uniwersytetu w Belgradzie, w ramach przyznanego projektu ERASMUS+ 2016-2-NL01KA107-034906.

\section{Literatura}

[1] Dagdeviren M.: Decision making in equipment selection: an integrated approach with AHP and PROMETHEE, „Journal of Intelligent Manufacturing” 2008, 19: 397-406. 
[2] Lin Z.C., Yang, C.B.: Evaluation of machine selection by the AHP method, „Journal of Materials Processing Technology” 1996, 57: 253-258.

[3] Paramasivam V., Senthil V., Rajam Ramasamy N.: Decision making in equipment selection: an integrated approach with digraph and matrix approach, AHP and ANP, „International Journal of Advanced Manufacturing Technology" 2011, 54: 1233-1244.

[4] Bascetin A.: A decision support system for optimal equipment selection in open pit mining: analytical hierarchy process, „Istanbul Üniversitesi, Mühendislik Fakültesi Yer Bilimleri Dergisi" 2003, 16, 2: 1-11.

[5] Mohamadabadi H.S., Tichkowsky G., Kumar A.: Develop ment of a multi-criteria assessment model for ranking of renewable and non-renewable transportation fuel vehicles, „Energy" 2009, 24, 1: 112-125.

[6] Cebesoy T.: Hydraulic Excavator Selection Using Improved Quality Comparison Method, „Journal of Engineering Sciences (Mühendislik Bilimleri Dergisi)" 1999, 5, 1: 1001-1008.

[7] Hadi-Vencheha A., Mohamadghasemi A.: A new hybrid fuzzy multi-criteria decision-making model for solving the material handling equipment selection problem, „International Journal of Computer Integrated Manufacturing” 2015, 28, 5: $534-550$.

[8] Basu A.S., Lineberry G.T.: Selection of Mobile Equipment for Underground Coal Mining: An Expert System Approach, „Mineral Resources Engineering" 1995, 4, 1: 71-88.

[9] Delgado M., Verdegay J.L., Vila M.A.: Linguistic decisionmaking models, „International Journal of Intelligent Systems" 1992, 7: 479-492.

[10] Hwang C.L., Yoon K.P.: Multiple Attributes Decision Making: Methods and Applications, Springer, Berlin - Heidelberg 1981.

[11] Kaufmann A., Gupta M.M.: Introduction to Fuzzy Arithmetic. Theory and Applications, Van Nostrand Reinhold, New York 1991.

[12] Liu S., Lin Y.: Grey systems Theory and Applications, Springer, Berlin - Heidelberg 2010.
[13] Bhattacharyya R.: A Grey Theory Based Multiple Attribute Approach for $R \& D$ Project Portfolio Selection, „Fuzzy Information and Engineering" 2015, 7: 211-225.

[14] Li G-D. et al.: A grey-based decision-making approach to the supplier selection problem, „Mathematical and Computer Modelling" 2007, 46: 573-581.

[15] Milisavljević V., Medenica D., Čokorilo V., Ristović I.: New Approach to Equipment Quality Evaluation Method with Distinct Function, „Thermal Science” 2015, 20, 2: 743-752.

prof. VLADIMIR MILISAVLJEVIĆ Faculty of Mining and Geology

University of Belgrade

Đušina 7, 11000 Belgrade,

Serbia

vladimir.milisavljevic@rgf.bg.ac.rs

prof. ALBERTO MARTINETTI

Faculty of Engineering Technology

University of Twente

PO BOX 217, 7500 AE Enschede,

Netherlans

a.martinetti@utwente.nl

prof. ALEKSANDAR CVJETIĆ

Faculty of Mining and Geology

University of Belgrade

Đušina 7, 11000 Belgrade,

Serbia

aleksandar.cvjetic@rgf.bg.ac.rs 